\title{
EL NIVEL EPISTEMOLÓGICO DE LAS CIENCIAS MEDIAS EN EL PENSAMIENTO DE TOMÁS DE AQUINO
}

\author{
José María Petit Sullá \\ Universidad de Barcelona
}

En su célebre estudio sobre el objeto y los límites de la Filosofía de la Naturaleza, Maritain aporta una cita de Santo Tomás, en su comentario a la Física de Aristóteles, donde afirma que las llamadas ciencias medias tienen un estatuto epistemológico que las sitúa más entre las ciencias físicas, o naturales, que entre las puramente matemáticas.

Como Maritain refiere, se trata de un comentario a un pasaje aristotélico de dudosa traducción, el «el fiskótera ton mathematon» que, en la versión latina manejada por el aquinate, rezaba «magis naturales quam matematicae». La traducción sin duda más correcta sería algo así como «magis naturales mathematicorum», según se desprende de las palabras del propio profesor francés, y la que de hecho hoy se admite como válida. Dice así el texto mariteniano. ${ }^{1}$

Digamos de entrada que, más que mal entendido el texto aristotélico fue mal traducido. En realidad, y desde un punto de vista estrictamente filológico la traducción correcta no es tan clara pues hay que advertir que (Maritain escribe su libro, la primera edición francesa, en

1 Santo Tomás advierte en su comentario al segundo libro de la Física de Aristóteles que estas ciencias, aún siendo formalmente matemáticas, son sin embargo preferentemente físicas porque, dice, su término -el término en que se perfeccionan, en que se verifica el juicio-, es la naturaleza sensiblę.

Abramos un paréntesis de orden histórico. Aristôteles, en realidad, no ha dicho esto expresamente; 10 ha dicho Santo Tomás apoyándose en un texto de Aristóteles mal entendido para gran provecho nuestro. Aristóteles en su libro II de la Física, cap. 2, 194 a 7, habla del conocimiento matemático y menciona las partes de las matemáticas que son más físicas que las otras, que conciernen preferentemente a las cosas físicas; lo que él llama «Ta Fisikotera Ton Mathematon», y los traductores modernos traducen con razón: «las partes más físicas de las matemáticas». Santo Tomás por el contrario, en su tercera lección sobre el libro II de la Física, entiende que no se trata de las partes más físicas de las matemáticas, sino de ciencias más físicas que matemáticas, magis naturales quam mathematicae. Esto ha permitido a Santo Tomás enunciar un importantísimo punto de doctrina y es éste: aun siendo formalmente matemáticas estas ciencias son preferentemente físicas: quia harum scientiarum consideratio terminatur ad materiam naturalem, licet per principia mathematica procedant (J. Maritain: Filosofía de la Naturaleza, p. 51-52, Ed. Club de Lectores, B.A. 1967). 
1936), se puede ver una traducción del texto aristotélico, en la línea de la latina manejada por Santo Tomás, en la versión inglesa de Cambridge, Massachussets, de la Harward University Press realizada por Cornford. En todo caso, la traducción más correcta es, en caso de duda, la que viene impuesta por el conjunto del pensamiento aristotélico y, en este sentido, no puede caber duda de que la interpretación más correcta -la que es más conforme con la globalidad del pensamiento del Estagirita- es la de que las ciencias medias son «las más físicas de las matemáticas», puesto que era común tesis de toda la antigüedad (por cierto tan bien argumentada por el propio Descartes, siglos después, en la Regla IV) que las matemáticas eran una ciencia amplia que contenía en sí una gama gradual de diversas ciencias, desde la aritmética y geometría hasta la mecánica, pasando por las citadas en el célebre pasaje que comentamos, la astronomía, la óptica y la música. Es en este sentido que se expresa Aristóteles en la Metafísica pero no vamos a exponerlo aquí puesto que ese estudio versa sobre el pensamiento de Santo Tomás.

Sin embargo, Maritain califica de error provechoso la susodicha equívoca interpretación, puesto que ofrece una oportunidad al intérprete de Aristóteles para mostrar alguna razón en favor de la tesis del carácter predominantemente físico de las ciencias medias. Este argumento será el del término en el cual se concluye la investigación en estas ciencias, es decir, las cosas naturales. Esta consideración es especialmente grata a Maritain quien en su obra defiende el carácter especificamente de las ciencias por el término al que se refieren, con mayor énfasis que el modo según el cual argumentan.

Todo este tema puede ser objeto de un peculiar y nada inútil debate en el que, aportados todos los textos y argumentos, de estos y otros autores -Kant entre ellos- se mostraría sin dificultad el carácter predominantemente matemático de las llamadas ciencias matemáticas de la naturaleza. En realidad, el mismo Maritain, en el conjunto de su obra admite, muy elocuentemente, que las ciencias medias de los escolásticos son en realidad formalmente matemáticas y sólo materialmente físicas. A este respecto, pues, el mundo conceptual de lo físico-matemático es una determinada región del más amplio mundo matemático, como lo ilustra Maritain en dicha obra, incluso con la ayuda de expresivos esquemas gráficos.

¿A qué viene, pues, el interés mariteniano, en mostrar el juicio de Santo Tomás, sobre la prioridad de lo terminativo o referencial sobre el modo científico de proceder? Entrar en este debate sería no tanto explicar el pensamiento de Santo Tomás como el del propio Maritain quien, evidentemente, a pesar de sus reiteradas y sinceras proclamaciones de tomismo se aparta aquí del pensamiento del santo, como espero probar en este trabajo. Sin embargo, si se atiende a lo dicho por Maritain, parece que el genuino discurrir del filósofo medieval se encasilla definitivamente en esta posición, si se atiene sólo al comentario a este pasaje. Y esta es la posición que hay que corregir de la mano de otro texto donde no se dé el constreñimiento de un pasaje supuestamente de genuino aristotelismo. Dicho texto alternativo existe en la Suma Teológica.

En efecto, en la Suma Teológica Santo Tomás expone la prioridad de lo formal sobre lo material en las ciencias y, por consiguiente, en el caso que nos ocupa, de la prioridad de lo 
formal, esto es, los principios matemáticos sobre lo puramente material, es decir, aquello sobre lo que versa una ciencia. Dicho criterio está de tal modo asumido por el santo que le sirve de argumento para probar una cuestión teológica. Y ahí radica la prioridad de este texto sobre el comentario a la Física aristotélica, porque de tal manera se ha asumido el criterio formal que sirve, como decimos, de paradigma para explicar que la referencia, en última instancia, a Dios del conocimiento de las cosas naturales no convierte por ello al don de ciencia en un don formalmente dirigido al conocimiento de Dios. En efecto, la dificultad propuesta reza así; si el don de ciencia lleva en último término a Dios se ha de tener por una ciencia de lo divino, es decir, una sabiduría, desde el punto de vista de los dones del Espíritu Santo. Así, pues, no existe la ciencia como don específicamente diferente de la sabiduría, pues aunque pasa por las criaturas a quienes se refiere formalmente el dicho don del Espíritu Santo, sin embargo si, como dice San Pablo, a través de lo visible llegamos al conocimiento de lo invisible, el don de ciencia aunque formalmente mire el saber de las cosas de este mundo más se ha de contar como ciencia de Dios puesto que es en $\mathrm{El}$ en que termina este saber. A esta objeción responde así. ${ }^{2}$

El efecto del texto de la Física no deja de sentirse también en el que aquí se ha expuesto. Tomás lo tiene bien presente e incluso parece que aún siendo ajeno al tema del artículo no quiere dejar de referirlo. Las ciencias que miran las cosas naturales, según dice el Filósofo, son más naturales que matemáticas. Pero salvada esta «razón» de autoridad, el pensamiento del autor va por el camino opuesto: lo formal es potius, más potente que lo material y por ello las ciencias medias se han de contar entre las matemáticas como aquéllas con las que son similiores, más semejantes. No puede caber ninguna duda en esto, la semejanza con las matemáticas es superior a la relación que puedan tener con las ciencias físicas. El modo de argumentar, esto es, el medium per quod aliquid cognoscitur es lo realmente constitutivo de una ciencia aunque luego este conocimiento «se aplique» a cosas materiales. La aplicación no es lo que constituye a una ciencia, pues materialmente los objetos pueden ser muy diversos, sino el modo de razonar, el tipo de argumentación que, en el caso de las ciencias medias, las ciencias matemáticas de la naturaleza, es el modo matemático.

Hay que advertir que este texto es del todo opuesto a la tesis de Maritain, pues expresamente señala que el término de una ciencia, aquello en lo que finalmente recae no es lo formalmente determinante de la misma. Es siempre el modo de argumentar, los «principia abstracta» de su proceder, los que determinan el estatus de una ciencia. La conclusión teológica citada en último lugar es del todo significativa. En efecto, un saber divino, aunque arroja luz sobre las cosas humanas, es un saber sapiencial y no científico, es el don de sabiduría

2 Ad tertium dicendum quod sicut supra (q. 1, a. 1) dictum est, quilibet cognoscitivus habitus formaliter quidem respicit medium per quod aliquid cognoscitur, materialiter autem id quod per medium cognoscitur. Et quia id quod est formale potius est, ideo illae scientiae quae ex principiis mathematicis concludunt circa materiam naturalem, magis cum mathematicis connumerantur, utpote eis similiores; licet quantum ad materiam magis conveniat cum naturali, et propter hoc dicitur in II Physica quod sunt magis naturales. Et ideo cum homo per res creatas Deum cognoscit, magis videtur hoc pertinere ad scientiam, ad quam pertinet formaliter, quam ad sapientiam, ad quam pertinet materialiter. Et e converso, cum secundum res divinas iudicamus de rebus creatis, magis ad hoc sapientiam quam ad scientiam pertinet (S.T. II-II, q. 9, ar. s, ad 3). 
y no el don de ciencia. Así, podría aplicarse este criterio exactamente a las ciencias medias. Aunque arrojen luz sobre la naturaleza, pues a ella se refieren como a su término, son más bien ciencias matemáticas pues su formalidad, sus principios, son los de una ciencia matemática.

Se podría objetar desde una posición genérica que el lugar específico en que Santo Tomás trata la cuestión debatida es el comentario a la Física de Aristóteles y que en caso de disparidad este comentario debe prevalecer como texto dirimente sobre otras posibles interpretaciones. Pensamos, sin embargo, más bien al revés, que el genuino pensamiento de Santo Tomás se halla más en la obra teológica que en los comentarios a las obras de Aristóteles, puesto que en éstas se ejerce sólo de comentador mientras en aquella se pone la propia filosofía al servicio de un saber teológico superior. Y es el pensamiento de Tomás de Aquino lo que se intenta esclarecer. Este criterio, no obstante, acepto que tiene que matizarse en cada caso singular por el contexto total.

Pero precisamente en el caso debatido existe una partícula que explicita suficientemente el pensamiento global del aquinate. En efecto, en el comentario a la Física, escribe Santo Tomás de manera bien clara: «dictur hic a philosopho». Este adverbio no lo puso Tomás para reforzar el sentido puramente gramatical, sintáctico, pues sería superfluo decir que el Filósofo dice «aquí»-puesto que siempre se habla aquí y ahora- sino para singularizar la posición de Aristóteles que «aquí» (y sólo aquî) considera a las ciencias medias como más físicas que matemáticas. Veamos para ello la totalidad del texto tomista al que Maritain se refiere pero que cita sólo muy parcialmente. Dicha totalidad nos esclarecerá algo este comentario que, pese a la deficiente traducción antes señalada, tiene no obstante un valor innegable. ${ }^{3}$

No se trata sólo de la advertencia circunstancial de que este pensamiento sólo se expresa «aquí», existe además, en la visión panorámica del fragmento otra señal significativa. Tomás de Aquino dice «unumquodque denominatur et speciem habet a termino» sin que estas expresiones puedan ser entendidas como determinaciones formales sino precisamente especificativas y, más aún, denominativas. Y en este sentido no sólo hay una razón de salvar la coherencia aristotélica -siempre presente en Santo Tomás- sino también una razón objetiva. En efecto, cabe hablar de especificar un saber genérico por el término al que se refiere este saber y este criterio es el que se aplica -y se ha de aplicar-a las distinciones regionales. Esto es lo que distingue, por ejemplo a la astronomía de la óptica o de la acústica, como es obvio, por cuanto desde el punto de vista formal estas ciencias no se distinguirían una de otra. La referencia material de un saber actúa entonces como criterio especificador. Y esto es todo lo

3 Dicuntur autem scientiae mediae, quae accipiunt principia abstracta a scientis pure matemathicis, et applicant ad materiam sensibilem; sicut perspectiva applicant ad lineam visualem ea quae demonstrantur a geometria circa lineam abstractam; et harmonica, idest musica applicat ad sonos ea quae arithmeticus considerat .circa proportiones numerorum; et astrologia considerationem geometricae et arithmeticae applicat ad caelum et ad partes eius.

Huismodi autem scientiae, licet sint mediae inter scientiam naturalem et mathematicam, tamen dicuntur hic a Philosopho esse magis naturales quam mathematicae, quia unquodque denominatur et speciem habet a termino: unde, quia harum scientiarum consideratio terminatur ad materiam naturalem, licet per principia mathematica procedant, magis sunt naturales quam mathematicae (S. Thomas: In Phisicorum, L. II, 1. III). 
que Tomás de Aquino, el más grande comentador de Aristóteles puede decir en favor del «Filósofo» sin traicionar su propio pensamiento que, por otra parte es también el de Aristóteles, pues sólo una deficiente traducción pudo llevar a dudar de cuál es la tesis del que fue un gran lógico de las ciencias, Aristóteles.

En conclusión, por el sólo comentario a la Física no conoceríamos suficientemente el pensamiento de Tomás de Aquino respecto a la ubicación de las ciencias medias. Es preciso atender al texto citado de la Suma Teológica. Una vez más se prueba que un autor sintético, como lo es Santo Tomás, ha de ser conocido en su globalidad. La presentación de Maritain es original y sirve a su propósito pero desfigura, al menos por omisión, el genuino pensamiento tomista. 